\title{
ANALISIS MUSIM PENANGKAPAN IKAN TERI (Stolephorus sp.) DI TELUK DODINGA, KABUPATEN HALMAHERA BARAT
}

\author{
Alfret Luasunaung \\ Program Studi Pemanfaatan Sumberdaya Perikanan, \\ Fakultas Perikanan dan IImu Kelautan. UNSRAT. Manado 95115.
}

\begin{abstract}
Fisheries should be a sustainable economic activity in order to maintain itsa services in the future. Sustainable marine fisheries resources exploitation requires a utilization rate lower than the resources availability. Therefore, the exploitation/rate should not achieve the recovery ability of the resources in any particular period. in fishing activities, for instance, there is a guideline not to catch fish over the Dotal Allowable Catch (TAC), $80 \%$ of the MSY value.

The exploitation rate of the anchovy (Stolephorus sp.) in Dodingd Bay was still low. It could result from small-scaled traditional fishermen and low fishing distance from the shore. Their income was also low due to high operational cost and fluctuation in fish price. To improve the fishermen prosperity, it is necessary fo raise the fishing productivity and the efficiency of production input utilization on the boat lift net. This study focused on understanding the anchovy fishing season of the boat lift net in Dodinga Bay to analyze the yearly fishing seasons for the last five years.

Results concluded that the fishing season of the anchovy (Stolephorus sp.) in Dodinga Bay could be separated into two phases, March to June and October to November, but the former was more extensive and lager in scale than the later.
\end{abstract}

Keywords : Fishing season, total allowable catch(JAC), Dodinga Bay, Boat lift net

\section{PENDAHULUAN}

Perikanan tangkap merupakan salah satu kegiatan ekonomi perikanan dan kelautan di Propinsi Maluku Utara dán menjadi prime mover karena konstribusinya cukup besar bagi produksi perikanan dan kelautan secara umum. Salah-satu wilayah di Kabupaten Halmahera Barat yang memiliki potensi dan sumberdaŷa ikan pelagis kecil adalah Teluk Dødinga, dimana kegiatan perikanan tangkap berkembang dengan baik serta menjadi salah satu sumber produksi perikanan tangkap khususnya perikananbagan perahu.

Menuurut Dahuri (2002), pemanfaatan sumberdaya perikanan harus memperhatikan aspek sustainability, agar dapat memberikan manfaat yang sama, di masa datang, yang tidak hanya terfokus pada masalah ekonomi, tetapi juga masalah lain seperti teknis, sosial dan budaya. Tingkat pemanfaatan sumberdaya optimal melalui pendekatan Maximum Sustainable Yield (MSY) dan Maximum Economic Yield (MEY). Pendekatan MSY akan memberikan hasil lestari secara fisik, namun demikian dalam praktek pengelolaan sumberdaya perikanan, tingkat tangkapan MEY akan lebih baik, karena selain memberikan keuntugan secara ekonomi juga memberikan keuntungan secara ekologis. Pemanfaatan sumberdaya perikanan dan kelautan berkelanjutan menuntut pemanfaatan yang tidak melebihi ambang batas dari sumberdaya tersebut. Oleh karena itu, tingkat pemanfaatan sumberdaya tidak boleh melebihi kemampuan pulih (potensi lestari) sumberdaya dalam periode waktu tertentu. Dalam bidang perikanan tangkap misalnya, sudah ada pedoman bahwa tingkat pemanfaatan suatu stok ikan tidak boleh melebihi Total Allowable Catch (TAC) yaitu $80 \%$ dari nilai MSY-nya.

Besarnya potensi sumberdaya di perairan Teluk Dodinga ini menunjukkan bahwa permasalahan perikanan tangkap bagan, yang mentargetkan ikan teri (Stolephorus sp.) sebagai tujuan penangkapan masih rendah. Hasil tangkapan rendah karena pada umumnya merupakan nelayan tradisional atau berskala kecil sehingga daerah tangkapnya (fishing ground) terbatas tidak jauh dari pantai. Pendapatan 
nelayan rendah karena biaya operasional yang tinggi dan harga jual ikan yang berfluktuasi. Untuk memperbaiki kesejahteraan nelayan maka perlu adanya peningkatan pendapatan nelayan melalui peningkatan produktivitas, efisiensi penggunaan input produksi pada berbagai jenis perahu dan alat tangkap perikanan. Untuk itu permasalahan yang dapat dirumuskan dalam penelitian ini adalah bagaimana siklus musim penangkapan ikan teri pada perikanan bagan perahu di teluk Dodinga. Berdasarkan perumusan masalah tersebut, maka tujuan penelitian ini adalah menganalisis musim penangkapan ikan pada setiap tahun selama kurun waktu lima tahun terakhir.

Manfaat penelitian ini diharapkan dapat memberikan gambaran tentang kondisi dan status perikanan tangkap bagan di perairan Teluk Dodinga, sehingga dapat memberikan informasi kepada nelayan tentang pengembangan usahanya serta diharapkan juga penelitian ini dapat dijadikan sebagai bahan informasi yang dapat digunakan oleh pemerintah daerah dalam menentukan strategi pengelolaan dan pengembangan perikanan tangkap bagan perahu secara berkelanjutan.

\section{METODOLOGI PENELITIAN}

Penelitian ini dilaksanakan di perairan teluk Dodinga Kabupaten Halmahera Barat Propinsi Maluku Utara Waktu penelitian selama bulan Maret sampai Mei 2010. Peralatan dan bahan yahg digunakan dalam penelitian ini berapa! satu unit bagan perahu, kamera, kûesioner, alat tulis menulis, lampu dan perahu transport.

Metode yang digunakan dalam penelitian ini adalah metode survei bertujuan untuk mengumpulkan data dari sejumlah variabeł pada suatu kelompok masyarakat melălui wawancara langsung dan berpedomå pada daftar pertanyaan yang telah dipersiapkan. Data yang dikumpulkan adalah data primer dan data sekunder.

\section{Analisa Musim Penangkapan}

Secara sederhana musim ikan dalam setiap tahun merupakan periode (bulan) dimana jumlah hasil tangkapan lebih besar dari rata-rata hasil tangkapan selama periode tahun tersebut (Uktolseja, 1993).
Bila tersedia data untuk periode waktu (tahun) tertentu, maka analisis yang digunakan untuk menduga musim ikan adalah sebagai berikut:

$$
Y_{j}=\frac{1}{t} \sum Y_{i j}
$$

dimana:

$Y_{j}=$ rata-rata hasil tangkapan bulanan selama periode $t$ tahun

$\sum \mathrm{Y}_{\mathrm{ij}}=$ produksi bulanan pada bulan ke-j tahun-i

Musim ikan dapat diketahui dengan membandingkan $Y_{j}$ dengan rata-ráta hásil tangkapan total $(\bar{Y})$, jika:

$Y_{i j}>\bar{Y}$ berarti musim ikan
$Y_{i j}<\bar{Y}$ berarti tidak musim ikan
Nilai $\bar{Y}$ dapat dicari dengan

$\bar{Y}=\frac{1}{n} \sum Y_{i j}$

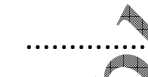

dimana:

$\mathrm{n}=\sum \mathrm{n}_{\mathrm{i}}=12$ bulan (1 tahtun).

Disadari bahwa data ilmiah tentang hasil tangkapan dari setiap nelayan pemilik alat tangkap tradisional sangat sulit diperolęh dan seringkali tidak lengkap. Oleh kerena itu asumsi yang mendasari penelitian ini adalah data hasil tangkapan yang tersedia dari beberapa nelayan dikombinasikan sehingga dapat digunakan untuk menganalisis pendugaan stok musim.

\section{HASIL DAN PEMBAHASAN}

\section{Deskripsi Lokasi Penelitian}

Desa Toniku adalah salah satu desa yang berada di Kecamatan Jailolo Selatan, Kabupaten Halmahera Barat, Provinsi Maluku Utara, yang memiliki luas desa 20 hektar dan terletak di pesisir. Batas-batas desa sebagai berikut: sebelah Utara berbatasan dengan Desa Tewe, sebelah Selatan dengan Desa Rioribati, sebelah Barat dengan Teluk Dodinga, sebelah Timur dengan Hutan Raya.

Secara administratif jumlah penduduk desa Toniku 854 jiwa terdiri dari lakilaki 454 jiwa dan perempuan 400 jiwa dengan jumlah kepala keluarga $226 \mathrm{KK}$. Masyarakat desa Toniku memiliki mata pencaharian yang sebagian besar adalah nelayan dan petani. Profesi nelayan relatif dominan karena terdapat sejumlah bagan dengan ukuran yang relatif besar, sehingga 
dapat menampung sebagian masyarakat dalam menggantungkan kehidupannya.

Faktor lingkungan perairan juga sangat mendukung usaha bagan perahu. Hal ini disebabkan kerena posisinya berada di kawasan teluk Dodinga yang relatif tidak terpengaruh oleh adanya gelombang yang besar. Selain itu terdapat berbagai macam ekosistem khas wilayah pesisir pantai seperti ekosistim mangrove, lamun dan karang. Kawasan Perairan Teluk Dodinga ini terdapat pula muara sungai Toniku dan sungai Tewe yang setiap saat meluap dan membawa serta unsur-unsur hara ke perairan. Kondisi ini menyebabkan lingkungan di kawasan perairan teluk relatif subur, sehingga berbagai biota perairan terutama ikan teri untuk menjadikan wilayah tersebut sebagai habitatnya.

Alat tangkap bagan merupakan jenis jaring angkat yang berbentuk empat persegi panjang yang dioperasikan pada malam hari dengan menggunakan sumber cahaya sebagai penarik perhatian ikan dan terdiri dari komponen-komponen penting, yaitu perahu, jaring, anjang-anjang, pemberat, jangkar, lampu, roller dan rumah bagan.

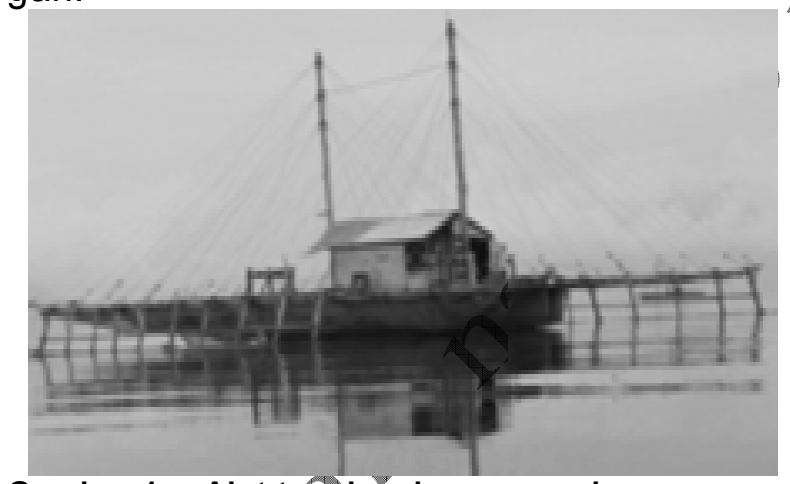

Gambar 1. Alat tangkap bagan perahu.

Alat tangkap bagan ini dioperasikan pada malam hari dengan menggunakan sumber cahaya sebagai penarik perhatian ikan. Biasanya nelayan melakukan operasi penangkapan ini sebanyak dua kali setting dan dua kali hauling dalam 1 trip penangkapan. Untuk teknik penangkapannya dilakukan dengan cara memutar roller yang fungsinya untuk menurunkan jaring dan menaikkan jaring. Pengoperasian satu unit alat tangkap bagan perahu di Perairan Teluk Dodinga membutuhkan 5 orang Anak buah Kapal (ABK). Tugas masing-masing ABK pada saat operasi penangkapan 1 orang mengatur tali jangkar pada saat hauling, 3 orang memutar roller, dan 1 orang mengatur pencahayaan lampu. Setting dimulai pada saat senja hari (pukul 18.00) setelah semua ujung jaring diikatkan pada bingkai jaring dan selanjutnya dilakukan penyalaan lampu. Sebelum bingkai jaring diturunkan, batu arus yang berfungsi sebagai penahan jaring diturunkan terlebih dahulu. Pertama-tama jaring (cang) yang terbuat dari bahan polyetylen (PE) diturunkan secara perlahan-lahan ke dalan perairan dengan cara mengulurkap tali-tali yang melilit pada badan roller dimana terdapat tali-tali penghubung ke bingkai jaring tempat penggantungan jaring di keempat sudut-sudut utamanya. Rada saat rangka menyentuh permukaan air, di bagian tengah jaring diberi pemerat dari batu (sekitar $30 \mathrm{~kg}$ ) agar jaring eepat turun ke dasar perairan.

\section{Pendugaan Musim Penangkapan Ikan}

Pendugaan musim penangkapan ikan teri di perairan Teluk Dodinga didasarkan pada rata-rata hasil tangkapan per satuan upaya bulanan selama periode waktu Yima tahun. Data ikan teri tiap bulan dan deviasinya selama periode waktu tersebut disajikan dalam Tabel 1 dan Tabel 2. Sedangkan pendugaan musim penangkapan ikan disajikan dalam Gambar 2 sampai Gambar 6.

Tabel 1. Hasil tangkapan bagan tiap bulan selama 5 tahun (satuan $\mathbf{k g}$ ).

\begin{tabular}{lrrrrr}
\hline \multirow{5}{*}{ Bulan } & \multicolumn{5}{c}{ Tahun pengoperasian bagan } \\
\cline { 2 - 6 } & $\mathbf{2 0 0 5}$ & $\mathbf{2 0 0 6}$ & $\mathbf{2 0 0 7}$ & $\mathbf{2 0 0 8}$ & $\mathbf{2 0 0 9}$ \\
& $\left(\mathbf{Y}_{\mathbf{1}}\right)$ & $\mathbf{( \mathbf { Y } _ { \mathbf { 2 } } )}$ & $\mathbf{( \mathbf { Y } _ { 3 } )}$ & $\mathbf{( \mathbf { Y } _ { \mathbf { 4 } } )}$ & $\mathbf{( \mathbf { Y } _ { \mathbf { 5 } } )}$ \\
\hline Januari & 0 & 2145 & 2110 & 2115 & 1985 \\
Februari & 2280 & 2320 & 2400 & 1950 & 2500 \\
Maret & 3765 & 2220 & 3420 & 2495 & 3075 \\
April & 3420 & 2510 & 3910 & 2570 & 2210 \\
Mei & 2625 & 3665 & 3710 & 3315 & 3245 \\
Juni & 2785 & 2250 & 3220 & 3780 & 2530 \\
Juli & 2905 & 2670 & 2530 & 3200 & 4100 \\
Aggustus & 2640 & 1885 & 2710 & 2080 & 1990 \\
September & 2145 & 2145 & 2460 & 1880 & 1600 \\
Oktober & 2530 & 2045 & 2445 & 2250 & 2545 \\
November & 2090 & 1750 & 2255 & 2800 & 1495 \\
Desember & 1920 & 1650 & 2150 & 2210 & 1735 \\
\hline Total & $\mathbf{2 9 1 0 5}$ & $\mathbf{2 7 2 5 5}$ & $\mathbf{3 3 3 2 0}$ & $\mathbf{3 0 6 4 5}$ & $\mathbf{2 9 0 1 0}$ \\
\hline Rataan & $\mathbf{2 6 4 6}$ & $\mathbf{2 2 7 1}$ & $\mathbf{2 7 7 7}$ & $\mathbf{2 5 5 4}$ & $\mathbf{2 4 1 8}$ \\
\hline
\end{tabular}

Gambar 2 menunjukkan bahwa musim penangkapan ikan teri pada tahun 2005 mencapai puncaknya pada bulan Maret, kemudian diikuti pada bulan April dan bulan Juli. 


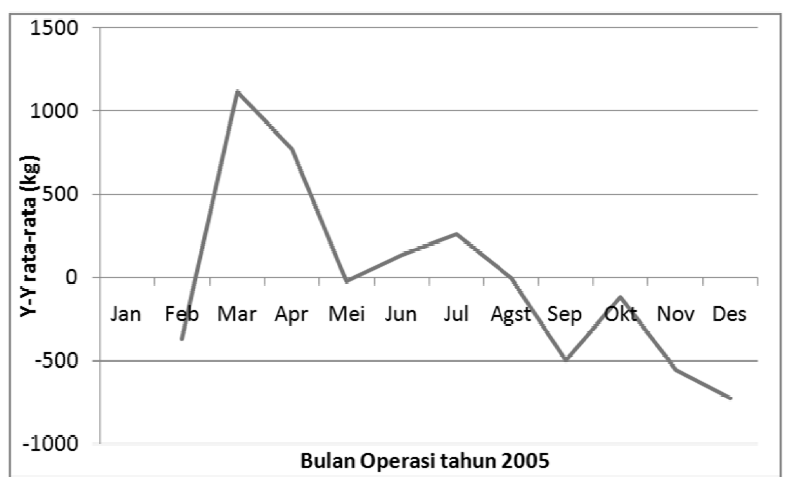

Gambar 2. Musim penangkapan ikan teri tahun 2005

Tabel 2. Deviasi hasil tangkapan bagan tiap bulan selama 5 tahun.

\begin{tabular}{lrrrrr}
\hline \multicolumn{7}{c}{ Bulan } & \multicolumn{6}{c}{ Tahun pengoperasian bagan } \\
\cline { 2 - 6 } & $\mathbf{2 0 0 5}$ & $\mathbf{2 0 0 6}$ & $\mathbf{2 0 0 7}$ & $\mathbf{2 0 0 8}$ & $\mathbf{2 0 0 9}$ \\
\hline Januari & - & -126 & -667 & -439 & -433 \\
Februari & -366 & 49 & -377 & -604 & 83 \\
Maret & 1119 & -51 & 643 & -59 & 658 \\
April & 774 & 239 & 1133 & 16 & -208 \\
Mei & -21 & 1394 & 933 & 761 & 828 \\
Juni & 139 & -21 & 443 & 1226 & 113 \\
Juli & 259 & 399 & -247 & 646 & 1683 \\
Agustus & -6 & -386 & -67 & -474 & -428 \\
September & -501 & -126 & -317 & -674 & -818 \\
Oktober & -116 & -226 & -332 & -304 & 128 \\
November & -556 & -521 & -522 & 246 & -922 \\
Desember & -726 & -621 & -627 & -344 & -683 \\
\hline
\end{tabular}

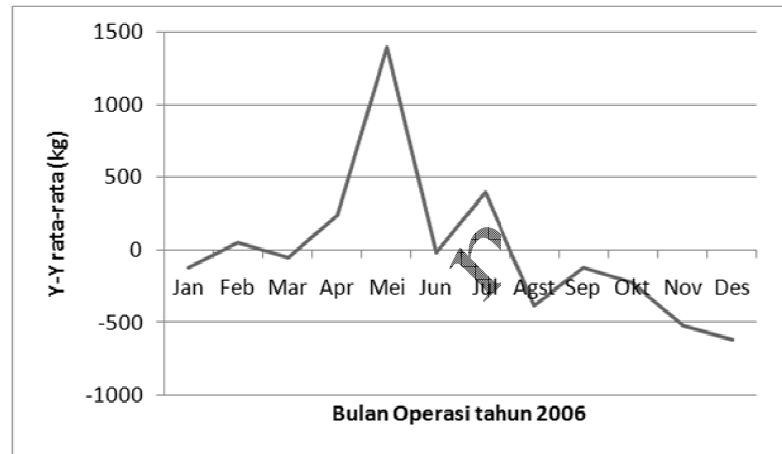

Gambar 3. Mưsìm penangkapan ikan teri tahun 2006

Musim penangkapan ikan pada tahun 2006 bergeser lebih lambat dari tahun sebélumnya (2005) dimulai dari bulan April dan mencapai puncak pada bulan Mei kemudian bulan Juli.

Musim penangkapan ikan pada tahun 2007 berlangsung lebih lama atau lebih luas yaitu dari bulan Maret sampai bulan Juni dan mencapai puncaknya pada bulan April.

Musim penangkapan ikan pada tahun 2008 berlangsung bulan Mei sampai bulan Juli dimana puncaknya pada bulan Juni dan sedikit pada bulan November.

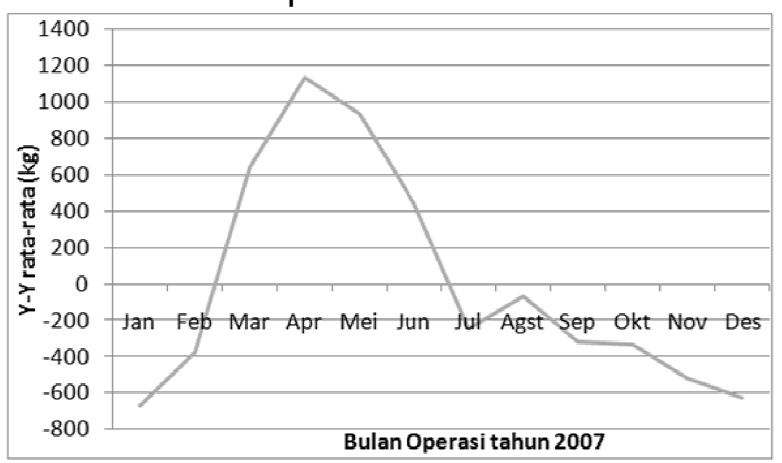

Gambar 4. Musim penangkapan ikañ teri tahun 2007

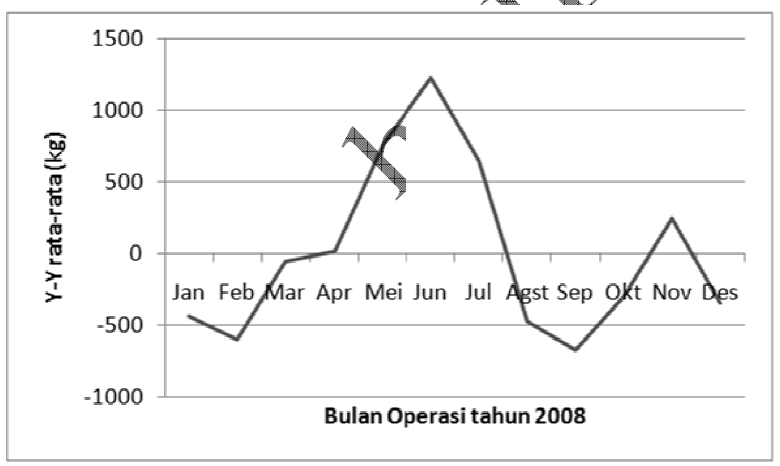

Gahbar'5. Musim penangkapan ikan teri tahun 2008

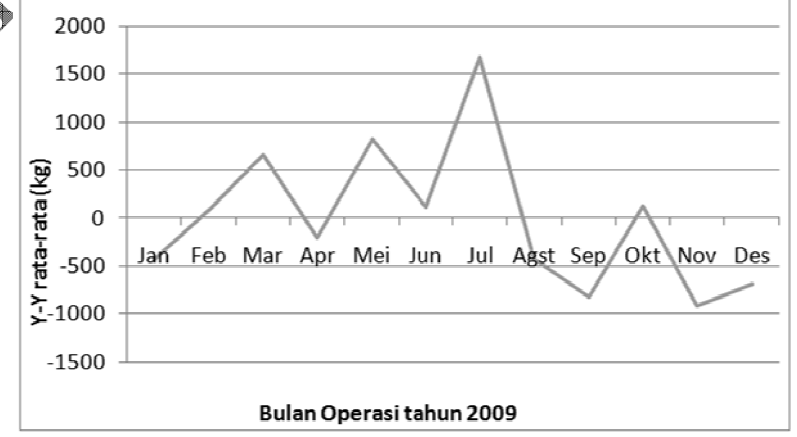

Gambar 6. Musim penangkapan ikan teri tahun 2009

Musim penangkapan ikan pada tahun 2009 berlangsung pada bulan Maret, bulan Mei dan mencapai puncaknya pada bulan Juli.

\section{Pembahasan}

Jumlah alat tangkap bagan yang beroperasi di perairan Teluk Dodinga sampai tahun 2010 sebanyak 12 unit dengan jumlah upaya rata-rata per tahun sebanyak 1176, memproduksi ikan teri sebesar 29,87 ton per tahun. Sedangkan dugaan potensi lestari (MSY) ikan teri di perairan tersebut sebesar 30,82 ton per tahun, dengan upaya optimum sebanyak 1178 trip. Hal ini me- 


\section{Musim Penangkapan Ikan Teri}

nunjukkan bahwa tingkat eksploitasi ikan teri telah berada pada puncak maksimum. Jika terjadi peningkatan upaya atau penambahan jumlah alat tangkap, maka catch per unit effort akan menurun dan cenderung mengarah pada kelebihan tangkap.

Puncak musim ikan pada tahun 2005 terjadi pada bulan Maret, kemudian diikuti pada bulan April dan Juli, pada tahun 2006 bergeser lebih lambat dari tahun sebelumnya (2005), dan mencapai puncak pada bulan Mei kemudian bulan Juli. Selanjutnya pada tahun 2007 berlangsung lebih lama atau lebih luas yaitu dari bulan Maret sampai bulan Juni dan mencapai puncaknya pada bulan April. Dan musim ikan pada tahun 2008 berlangsung bulan Mei sampai bulan Juli dimana puncaknya pada bulan Juni dan sedikit pada bulan November. Musim penangkapan ikan pada tahun 2009 berlangsung pada bulan Maret, bulan Mei dan mencapai puncaknya pada bulan Juli.

Bulan-bulan bukan musim ikan cenderung terjadi pada bulan Desember sampai dengan bulan Februari, dimana pada bulan-bulan tersebut bertiupnya angin barat dan bulan Agustus-September dimana pada saat itu biasanya bertiup angin timur. Pada bulan-bulan bukan musim ikan menyebabkan hasil tangkapan menurun, yang berarti memberikan kesempatan padajikan teri untuk memijah. Dari hasil wawancara menurut para nelayan, musim pancaroba hasil tangkapan yang didapat banyak.

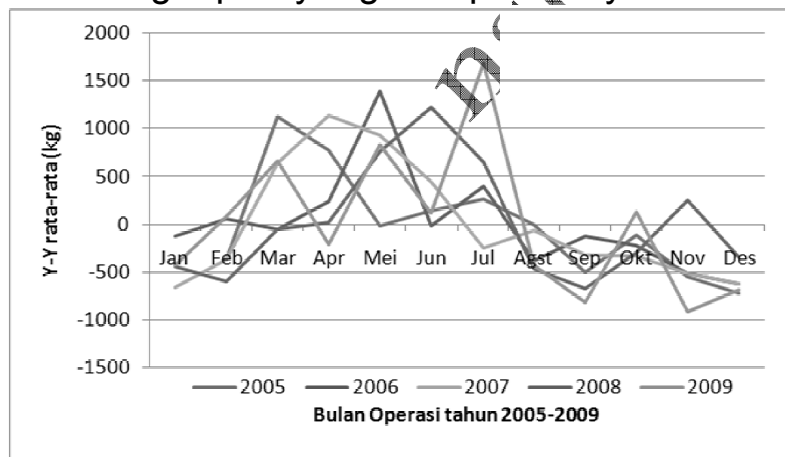

Gámbar 7. Musim penangkapan ikan teri selama 5 tahun.

Musim penangkapan ikan teri di perairan Teluk Dodinga sangat bervariasi pada setiap tahunnya, tetapi secara umum dapat dibagi ke dalam dua fase utama, yaitu fase pertama terjadi pada bulan Maret sampai dengan Juni; dan fase kedua terjadi pada bulan Oktober dan November; tetapi fase pertama jauh lebih luas dan lebih besar dibanding dengan fase kedua seperti terlihat dalam Gambar 7 di atas.

Ukuran bagan dan jumlah lampu tidak berpengaruh terhadap jumlah hasil tangkapan. Mungkin cahaya lampu saling mempengaruhi di antara unit bagan yang berdekatan pada kawasan perairan teluk yang terbatas.

\section{KESIMPULAN}

Berdasarkan hasil penélitian ini maka dapat disimpulkan bahwa musim penangkapan ikan teri (Stolephorus sp.) di Teluk Dodinga terbagi dalam dua fase, yaitu fase pertama terjadi pada bulan Maret sampai dengan Juni dân fase kedua terjadi pada bulan Oktober dan November, tetapi fase pertama jaúh lebih luas dan lebih besar dibanding dengan fase kedua.

\section{DÁFTAR PUSTAKA}

Dahuri, R, 2002. Membangun Kembali Perekonomian Indonesia Melalui Sektor Perikanan dan Kelautan. Lembaga Informasi dan Studi Pembangunan Indonesia. Jakarta,

Dahuri, R. J. 2003. Paradigma baru Pengembangan Indonesia Berbasis Kelautan. Operasi Ilmiah Guru Besar tetap Bidang Pengelolaan Sumberdaya Pesisir dan Kelautan Fakultas Perikanan dan IImu Kelautan Institut Pertanian Bogor, 133 hal.

Dinas Kelautan Perikanan Halmahera Barat. 2006. Statistik Perikanan Kab. Halmahera Barat. Provinsi Maluku Utara.

Ihsan, 2000. Kajian Model Pengembangan Usaha Perikanan Tangkap dalam rangka Pengelolaan Sumberdaya Perikanan Laut Secara Optimal di Daerah Kabupaten Pinrang Sulawesi Selatan. Tesis, Program Pascasarjan IPB. Bogor.

Kusumastanto, T. 1984. Pengembangan Usaha Penangkapan Ikan Cakalang di Perairan Utara Irian Jaya. Tesis Fakultas Pascasarjana IPB.

Monintja, D.R. 1994. Pengembangan Perikanan Tangkap Berwawasan Lingkungan. Makalah disampaikan Pada Seminar Pengembangan Agribisnis Perikanan Berwawasan 
Lingkungan pada Sekolah Tinggi Perikanan Jakarta. Agustus 1994. Jakarta.

Sudirman. 2004. Analisis Tingkah Laku Ikan untuk Mewujudkan Teknologi Ramah Lingkungan Dalam Proses Penangkapan pada Bagan Rambo (Tidak Dipublikasikan). Disertasi Program Pascasarjana Institut Pertanian Bogor. Bogor. 251 hal.
Uktolseja, J.C.B. 1993. Status Perikanan Ikan Pelagis Kecil dan Kemungkinan Pemanfaatannya sebagai Ikan Umpan Hidup untuk Perikanan Rawai Tuna di Prigi, Jawa Timur. Jurnal Pen. Perikanan Laut No. 80 Th. 1983.18 hal.

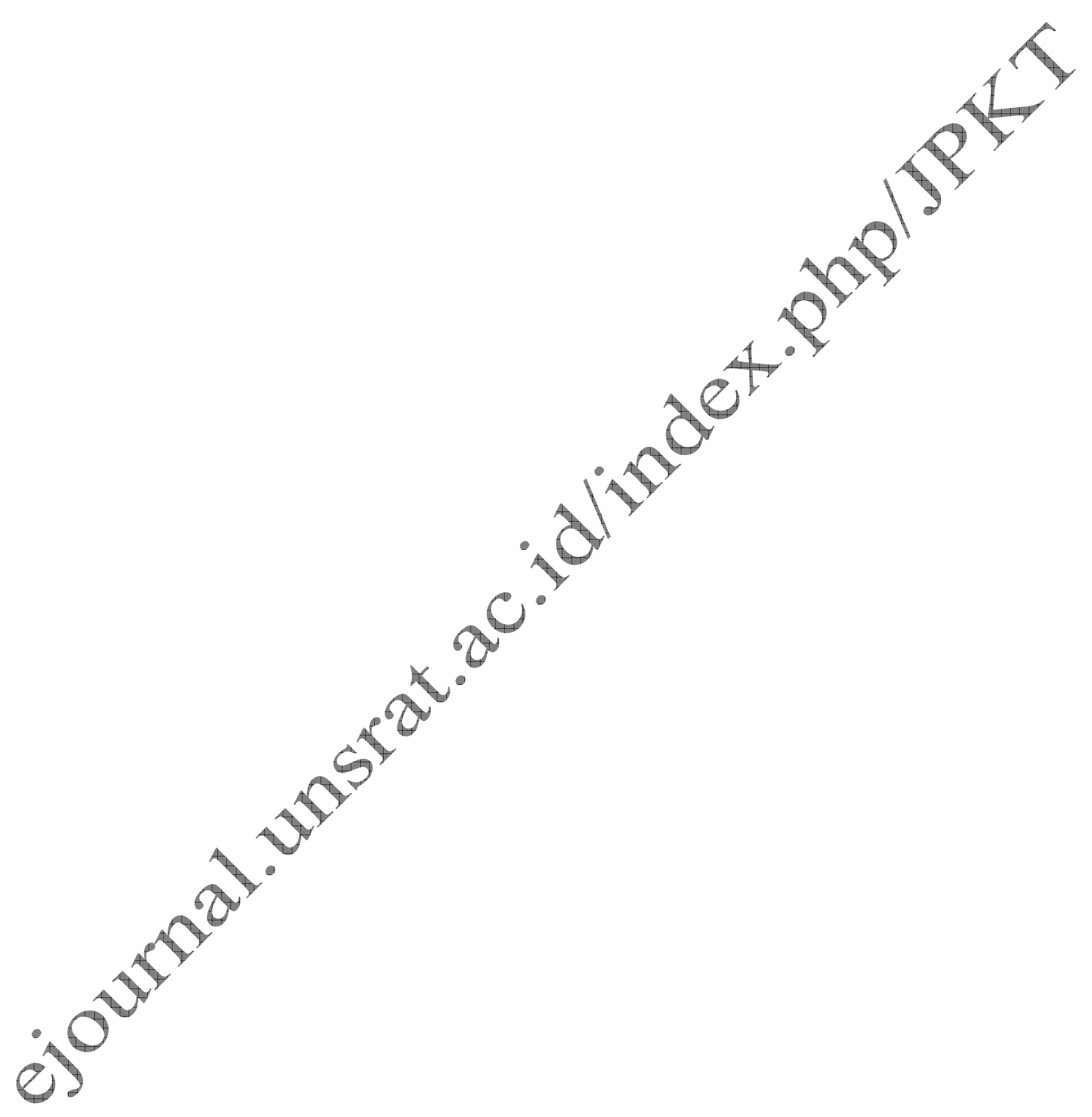

